\title{
Clinical Demographic Parameters and Dyslipidemia in Patients with Non-diabetic Coronary Heart Disease
}

\author{
Anuam Mangajan
}

\begin{abstract}
Background: Coronary heart disease is one of the most common causes of disability and mortality in the world and is a major preventable cause of death in India. Evidence showed role of dyslipidemia and Coronary artery disease (CAD) among type 2 diabetes but there is less evidence among non-diabetic CAD subjects. Present research is an attempt to Study of Clinico-demographic parameters and dyslipidemia among non-diabetic coronary artery disease patients. Material and Methods: A cross sectional study was carried out among 100 subjects with coronary artery disease without diabetes at a tertiary care centre. Dyslipidemia and Clinicodemographic parameters using anthropometric measurements studied among non diabetic coronary artery disease patients. Results: Maximum (32) subjects were in age group of 51-60yrs followed by 29 in 61-70yrs of age. Male were slightly predominant (53). Most (97) of the subjects were obese. There was no statistically significant difference in mean value of fasting and post prandial lipid parameters among male and female ( $p>0.05$ ) Conclusion: lifestyle modifications and behavioural change including weight reduction and abstinence from addiction like tobacco chewing, smoking and alcohol consumption. Post prandial lipid profile should also be targeted equally while treating coronary artery disease patients to prevent its future complications.
\end{abstract}

Keywords: Coronary artery disease, Dyslipidemia, Smoking

\section{Introduction}

Coronary heart disease is a worldwide health epidemic. Worldwide 30 percent of all deaths can be attributed to cardiovascular disease of which more than half are caused by coronary heart disease. Globally of those dying from cardiovascular disease, 80 percent are in developing countries. By 2020, cardiovascular disease will causes one of every three deaths worldwide. Coronary heart disease is the leading cause of cardiovascular disease. ${ }^{1,2}$

In comparison with the people of European ancestry, CVD affects Indians at least a decade earlier and in their most productive midlife years. ${ }^{3,4}$ For example, in Western populations only $23 \%$ of CVD deaths occur before the age of 70 years; in India, this number is $52 \% .^{5}$

In addition, case fatality attributable to CVD in low-income countries, including India, appears to be much higher than in middle- and high-income countries. ${ }^{6,7}$

The conventional risk factors for CAD can be divided into non modifiable and modifiable risk factors. The former include age, sex and family history, while the latter include diabetes mellitus (DM), smoking, dyslipidemia, hypertension and obesity. There is increasing incidence indicating that Asian Indians are at increased risk of CAD, which cannot be attributed to the common risk factors. ${ }^{8}$

Developing countries like India, coronary heart disease has emerged a prominent public health problem affecting especially men in the prime of their life, when their productivity, social and family responsibilities are the greatest. This has been attributed to rapid and widespread urbanization, industrialization, increased sedentary habits, use of automobiles for transport, increased smoking, and environmental pollution, consumption of diet rich in saturated fatty acids, refined carbohydrates and cholesterol. ${ }^{6}$
The burgeoning burden of CHD in India can be explained by the alarming rise in the prevalence of coronary risk factors like diabetes, hypertension, atherogenic dyslipidemia, smoking, central obesity and physical inactivity. Rapid urbanization and change in lifestyle that occurred during the past two decades have led to the growing burden of coronary risk factors in India. Previous studies conducted in migrant Indians were misinterpreted to indicate that conventional risk factors do not account for the high prevalence and premature occurrence of CHD among Indians; ${ }^{9}$ they were thought to be genetically preordained to develop the disease However, the large INTERHEART study which recruited significant number of Indian subjects found that the conventional risk factors accounted for most of the CHD burden. $^{9}$

Many clinical trials and meta-analyses have revealed that statin therapy targeting reduction of low-density lipoprotein cholesterol (LDL-C) decreases the risk of coronary heart disease (CHD) and all-cause mortality. ${ }^{10,11}$ However, a substantial number of cases of CHD are not prevented and residual risk factors remain unsettled. In particular, low high-density lipoprotein cholesterol (HDL-C) level and a high triglyceride (TG) level are considered to be important and residual risk factors. ${ }^{12}$

\section{Materials and Methods}

Place of study: tertiary care centre (Medicine/ Cardiology OPD/ Wards)

Type of study: Cross sectional observational study.

Sample size: 100 cases

A study by Krishnan MN ${ }^{[29]}$ found crude prevalence of definite CAD

in Kerala $5.8 \%$. With this prevalence at $95 \%$ confidence interval, using prevalence study sample size formula $\mathrm{n}=4 \mathrm{pq} / \mathrm{l}^{2}$

Where $\mathrm{P}=5.8 \%$

$\mathrm{q}=100-\mathrm{p} ; 94.2 \%$ 
$1=$ allowable error; $5 \%$ of $p$

Calculated sample size using win pepi software 84

Considering $10 \%$ no response rate 100 subjects were taken as final sample size.

Informed written consent was taken from patients.

Institutional Ethics Committee clearance was taken.

Sampling method: purposive sampling- All consecutive cases who meet the criteria will be included in study till desired sample size is obtained.

\section{Inclusion Criteria}

Patients above the age of 18 years, who are newly diagnosed cases of coronary artery disease and undergoing angiography coronary heart irrespective of sex, attending medicine OPD /IPD.

Patients with k/c/o IHD who were not on antilipid therapy.

Patients willing to be part of study.

\section{Exclusion Criteria}

Patients already on anti-hyperlipidemic agent/drugs.

Patients with hepatic disease, pancreatic disease, renal disease, hypothyroidism, Cushing's disease and inherited disorders of lipid metabolism.

Congenital heart disease.

Patients with diabetes

\section{Method of Study}

100 patients enrolled for study were explained the procedure and the purpose of the study, informed consent were taken from the patient. Required physical examination and necessary investigations were done.

\section{A] Physical examination:}

\section{Anthropometric measurements}

1) Height was measured using a wall mounted stadiometer to the nearest centimetre.

2) Subjects were made to stand erect after removing footwear, keeping their back against the wall, feet kept together, and eyes directed forwards.

3) Weight was measured using a portable electronic weighing machine after keeping on a firm horizontal surface. The subjects were required to wear light clothing and stand without footwear. Weight was noted in kilogram to the nearest $0.5 \mathrm{Kg}$.

4) Body mass index was calculated by taking weight in $\mathrm{kg}$ divided by height in meter squares. Subjects were categorized on BMI as follows: ${ }^{13}$

Underweight $-<18.5 \mathrm{Kg} / \mathrm{m}^{2}$

Normal- $18.5-22.9 \mathrm{Kg} / \mathrm{m}^{2}$

Overweight - 23-24.9 Kg/m ${ }^{2}$

Obese- $>25 \mathrm{Kg} / \mathrm{m}^{2}$

5) Waist circumference was noted using a nonstretchable measuring tape with subject standing upright in a relaxed position keeping both feet together. Circumference was measured at end of expiration, at the midpoint between the iliac crest and the lower margin of the ribs to the nearest centimetre.

6) Hip Circumference was measured using a nonstretchable measuring tape with subjects standing upright in a relaxed position keeping both feet together.
Hip Circumference was measured at widest part of buttocks to the nearest centimetre.

7) Waist to Hip ratio was calculated by waist and hip circumference measurements.

\section{B] Investigations:}

1) Electrocardiogram - A 12 lead electrocardiogram was done on all subjects in resting state by qualified professionals using three-channel digital ECG recorders with capacity to display measured ECG.

2) Fasting and post prandial lipid profile (TC, TG, LDL, VLDL, HDL)

Fasting lipid profile -blood was collected after overnight fasting

Post prandial- 4-hour after a standard meal. (The standard meal consisted of a diet that provided $600 \mathrm{~K}$ Calories). ${ }^{14}$

Serum total and HDL cholesterol and triglycerides (enzymatic colorimetric, Hitachi Roche Diagnostics,), LDL cholesterol calculated according to the Friedewald formula. ${ }^{13}$

3) Blood glucose level- was assessed as BSL random

4) Coronary angiography was performed, and severity of coronary artery measured in terms of single, double and Multivessel disease

\section{C] Clinico-demographic information:}

Using a designed interview questionnaire, history regarding significant socio-economic and demographic details, smoking habits, other addictions, physical activity, dietary habits, personal and family history of Ischaemic heart disease, Hypertension, dyslipidaemia, diabetes mellitus was recorded.

\section{Definitions:}

\section{Abdominal obesity:}

A] Abdominal obesity was defined as a waist circumference of more than or equal to $90 \mathrm{~cm}$ in men and $80 \mathrm{~cm}$ in women. $^{15}$

B] Abdominal obesity was defined as Waist to Hip ratio $>0.9$ in male or $>0.85$ in female. ${ }^{16}$

\section{Hypertension - cut off as}

A) Systolic blood pressure $\geq 140 \mathrm{~mm}$ of $\mathrm{Hg}$ and/or

B) Diastolic blood pressure of $\geq 90 \mathrm{~mm}$ of $\mathrm{Hg}$ and/or

C) Currently taking antihypertensive medication. ${ }^{17}$

3. Dyslipidaemia was defined as any of following: ${ }^{18}$

Total cholesterol levels above $200 \mathrm{mg} / \mathrm{dl}$,

HDL cholesterol levels less than $40 \mathrm{mg} / \mathrm{dl}$, and

Triglyceride levels higher than $150 \mathrm{mg} / \mathrm{dl}$

\section{Data analysis}

Data was collected using preformed data collection form and case record form. Data entry was done in Microsoft Excel and analysis using SPSS (Statistical Package for Social Sciences) Software version 20. Categorical variables were expressed in terms of frequency and percentage and continuous variables in terms of mean and SD. Association between severity of CAD and dyslipidaemia was analysed 
using chi square test and difference in lipid profile among CAD and Non CAD subjects was analysed using T test with $\mathrm{p}<0.05$ as statistically significant value at $95 \%$ Confidence interval.

\section{Results}

Table1: Age distribution of study subjects

\begin{tabular}{|c|c|c|}
\hline Age group & Frequency & Percent \\
\hline$<50 \mathrm{yrs}$ & 6 & 6 \\
\hline $51-60 \mathrm{yrs}$ & 32 & 32 \\
\hline $61-70 \mathrm{yrs}$ & 29 & 29 \\
\hline $71-80 \mathrm{yrs}$ & 27 & 27 \\
\hline$>80 \mathrm{yrs}$ & 6 & 6 \\
\hline Total & 100 & 100 \\
\hline
\end{tabular}

Table shows age distribution of study subjects. Maximum (32) subjects were in age group of 51-60yrs followed by 29 in 61-70yrs of age. Very few (6 each) subjects were $<50$ and $>80 \mathrm{yrs}$ of age. Mean age for study subjects was $65.45 \mathrm{yrs}$ and range of 43-86yrs.

Table 2: Gender distribution of study subjects

\begin{tabular}{|c|c|c|}
\hline Gender & Frequency & Percent \\
\hline Female & 47 & 47 \\
\hline Male & 53 & 53 \\
\hline Total & 100 & 100 \\
\hline
\end{tabular}

Table shows gender distribution of study subjects. Male were slightly predominant. M:F was $1.12: 1$

Table 3: BMI Classification of study subjects

\begin{tabular}{|c|c|c|}
\hline BMI Cat & Frequency & Percent \\
\hline Obese & 97 & 97 \\
\hline Overweight & 3 & 3 \\
\hline Total & 100 & 100 \\
\hline
\end{tabular}

Table shows BMI wise distribution of study subjects. Most (97) of the subjects were obese.

Table 4: Waist Circumference (WC) Categorisation of study subjects

\begin{tabular}{|c|c|c|}
\hline WC Raised & Frequency & Percent \\
\hline No & 34 & 34 \\
\hline Yes & 66 & 66 \\
\hline Total & 100 & 100 \\
\hline
\end{tabular}

Table shows 66 were having raised waist circumference.

Table 5: Waist to Hip Ratio (WHR) of study subjects

\begin{tabular}{|c|c|c|}
\hline WHR & Frequency & Percent \\
\hline No & 21 & 21 \\
\hline Yes & 79 & 79 \\
\hline Total & 100 & 100 \\
\hline
\end{tabular}

Table shows 79 had raised waist to hip ratio.

Table 6: Addictions among study subjects

\begin{tabular}{|c|c|c|}
\hline Addictions & Frequency & Percent \\
\hline Tobacco chewer & 51 & 51 \\
\hline Smoking & 36 & 36 \\
\hline Alcohol & 30 & 30 \\
\hline
\end{tabular}

Table shows most common addiction among study subjects was tobacco chewing (51\%) followed by smoking (36\%) and alcoholism (30\%).

Table 7: Relation of age and coronary artery disease (CAD)

\begin{tabular}{|c|c|c|c|c|}
\hline \multirow{2}{*}{ Age group } & \multicolumn{3}{|c|}{ CAD } & \multirow{2}{*}{ Total } \\
\cline { 2 - 5 } & SVD & DVD & TVD & \\
\hline \multirow{2}{*}{$<50 \mathrm{yrs}$} & 0 & 1 & 5 & 6 \\
\cline { 2 - 5 } & $0.00 \%$ & $16.70 \%$ & $83.30 \%$ & $100.00 \%$ \\
\hline \multirow{2}{*}{$51-60 \mathrm{yrs}$} & 1 & 9 & 22 & 32 \\
\cline { 2 - 5 } & $3.10 \%$ & $28.10 \%$ & $68.80 \%$ & $100.00 \%$ \\
\hline \multirow{2}{*}{$61-70 \mathrm{yrs}$} & 4 & 11 & 14 & 29 \\
\cline { 2 - 5 } & $13.80 \%$ & $37.90 \%$ & $48.30 \%$ & $100.00 \%$ \\
\hline \multirow{2}{*}{$71-80 \mathrm{yrs}$} & 15 & 11 & 1 & 27 \\
\cline { 2 - 5 } & $55.60 \%$ & $40.70 \%$ & $3.70 \%$ & $100.00 \%$ \\
\hline \multirow{2}{*}{$>80 \mathrm{yrs}$} & 4 & 2 & 0 & 6 \\
\cline { 2 - 5 } & $66.70 \%$ & $33.30 \%$ & $0.00 \%$ & $100.00 \%$ \\
\hline \multirow{2}{*}{ Total } & 24 & 34 & 42 & 100 \\
\cline { 2 - 5 } & $24.00 \%$ & $34.00 \%$ & $42.00 \%$ & $100.00 \%$ \\
\hline
\end{tabular}

Table shows relation of age and coronary artery disease (CAD). Among subjects with age group of <50yrs $83.3 \%$ were having TVD, $16.7 \%$ were having DVD. Among subjects with age group of 51-60yrs $68.8 \%$ were having TVD, $28.1 \%$ were having DVD and $3.1 \%$ were having SVD. Among subjects with age group of $61-70 y r s ~ 48.3 \%$ were having TVD, $37.9 \%$ were having DVD and $13.8 \%$ were having SVD. Among subjects with age group of 71-80yrs $3.1 \%$ were having TVD, $33.3 \%$ were having DVD and $66.7 \%$ were having SVD. Among subjects with age group $>80$ yrs $33.3 \%$ were having DVD and $66.7 \%$ were having SVD.

Table 8: Relation of gender and coronary artery disease

\begin{tabular}{|c|c|c|c|c|}
\hline \multirow{2}{*}{ Gender } & \multicolumn{3}{|c|}{ CAD } & \multirow{2}{*}{ Total } \\
\cline { 2 - 5 } & SVD & DVD & TVD & \\
\hline \multirow{2}{*}{ Female } & 13 & 14 & 20 & 47 \\
\cline { 2 - 5 } & $27.70 \%$ & $29.80 \%$ & $42.60 \%$ & $100.00 \%$ \\
\hline \multirow{2}{*}{ Male } & 11 & 20 & 22 & 53 \\
\cline { 2 - 5 } & $20.80 \%$ & $37.70 \%$ & $41.50 \%$ & $100.00 \%$ \\
\hline \multirow{2}{*}{ Total } & 24 & 34 & 42 & 100 \\
\cline { 2 - 5 } & $24.00 \%$ & $34.00 \%$ & $42.00 \%$ & $100.00 \%$ \\
\hline
\end{tabular}

Table shows relation of gender and coronary artery disease (CAD). Among male $41.5 \%$ were having TVD, $37.7 \%$ were having DVD, 20.8\% were having SVD. Among female subjects $42.6 \%$ were having TVD, $29.8 \%$ were having DVD and $27.7 \%$ were having SVD. There was no significant difference in $\mathrm{CAD}$ with reference to gender distribution among study subjects $(\mathrm{p}=0.617)$

Table 9: Relation of fasting lipid profile and gender

\begin{tabular}{|c|c|c|c|}
\hline Fasting Lipid Profile & Gender & Mean & p value \\
\hline \multirow{2}{*}{$\begin{array}{c}\text { F. Total Cholesterol } \\
(\mathrm{mg} / \mathrm{dl})\end{array}$} & Female(47) & $191.55 \pm 23.01$ & \multirow{2}{*}{0.737} \\
\cline { 2 - 3 } $\begin{array}{c}\text { F. Triglycerides (mg/dl) }) \\
\text { Fale(53) }\end{array}$ & $189.91 \pm 25.62$ & \\
\cline { 2 - 3 } & Memale(47) & $170.55 \pm 25.54$ & \multirow{2}{*}{0.324} \\
\hline \multirow{2}{*}{ F. HDL (mg/dl) } & Female(47) & $165.21 \pm 28.08$ & \\
\cline { 2 - 3 } & Male(53) & $41.3 \pm 3.10$ & \multirow{2}{*}{0.256} \\
\hline \multirow{2}{*}{ F. VLDL (mg/dl) } & Female(47) & $34.11 \pm 5.11$ & \multirow{2}{*}{0.324} \\
\cline { 2 - 3 } & Male(53) & $33.04 \pm 5.61$ & \\
\hline \multirow{2}{*}{ F. LDL (mg/dl) } & Female(47) & $116.14 \pm 21.05$ & \multirow{2}{*}{0.966} \\
\cline { 2 - 3 } & Male(53) & $116.33 \pm 23.33$ & \\
\hline
\end{tabular}


Table shows relation of fasting lipid profile and gender. There was no statistically significant difference in mean value of fasting lipid parameters among male and female ( $>0.05)$.

Table 10: Relation of post prandial lipid profile and gender

\begin{tabular}{|c|c|c|c|}
\hline $\begin{array}{c}\text { Post prandial lipid } \\
\text { profile }\end{array}$ & Gender & $\begin{array}{c}\text { Mean } \pm \text { Std. } \\
\text { Deviation }\end{array}$ & p value \\
\hline $\begin{array}{c}\text { PP. Total Cholesterol } \\
(\mathrm{mg} / \mathrm{dl})\end{array}$ & Female(47) & $221.62 \pm 24.89$ & \multirow{2}{*}{0.774} \\
\cline { 2 - 3 } $\begin{array}{c}\text { PP. Triglycerides } \\
(\mathrm{mg} / \mathrm{dl})\end{array}$ & Male(53) & $220.23 \pm 23.43$ & \\
\cline { 2 - 3 } & Male(53) & $197.17 \pm 22.25$ & \multirow{2}{*}{0.206} \\
\hline \multirow{2}{*}{ PP. HDL (mg/dl) } & Female(47) & $36.02 \pm 2.94$ & \multirow{2}{*}{0.615} \\
\cline { 2 - 3 } & Male(53) & $35.7 \pm 3.4$ & \\
\hline \multirow{2}{*}{ PP. VLDL (mg/dl) } & Female(47) & $39.43 \pm 4.45$ & \multirow{2}{*}{0.206} \\
\cline { 2 - 3 } & Male(53) & $38.26 \pm 4.72$ & \multirow{2}{*}{0.981} \\
\hline \multirow{2}{*}{ PP. LDL (mg/dl) } & Female(47) & $146.16 \pm 22.84$ & \\
\cline { 2 - 3 } & Male(53) & $146.26 \pm 21.60$ & \\
\hline
\end{tabular}

Table shows relation of post prandial lipid profile and gender. There was no statistically significant difference in mean value of post prandial lipid parameters among male and female $(\mathrm{p}>0.05)$.

\section{Discussion}

Coronary artery disease (CAD), also known as Ischaemic heart Disease (IHD) is defined as the reduction of blood flow to the cardiac muscle due to formation of plaques in the arteries supplying heart. It is the most widespread cardiovascular disease across all age groups. With the industrialization, urbanisation and change in lifestyle nowadays incidence of coronary artery diseases is found among younger generation and this is increasing burden for developing countries. In India, almost two-thirds of the burden among Non-communicable disease mortality is currently caused by cardiovascular disease related conditions. ${ }^{15}$

Hypertension, dyslipidemia, obesity and diabetes mellitus are among common cardiovascular risk factors. Their prevalence varies widely between different countries and important secular trends can be studied. ${ }^{8}$

Present study was an attempt in a metro city of India to study the clinico demographic parameters among nondiabetics coronary artery disease patients admitted in a tertiary care hospital.

Demographic profile of study participants revealed that maximum (32) subjects were in age group of 51-60 yrs followed by 29 in 61-70yrs of age. Very few (6 each) subjects were $<50$ and $>80 y$ rs of age. Mean age for study subjects was $65.45 \mathrm{yrs}$ and range of $43-86 \mathrm{yrs}$. Male was slightly predominant. M: F was 1.12:1. Most (97) of the subjects were obese.

In this study most (97) of the subjects were obese according to BMI classification, 79 had raised waist to hip ratio and 66 were having raised waist circumference. Studies have shown increased postprandial Triglyceride Rich Lipoprotein to be related to coronary artery disease in diabetic and nondiabetic subjects. ${ }^{19}$ Obesity being an independent marker for $\mathrm{CAD}$ in Asian diabetic population may be an important factor, but data is limited in Asian population. Obesity is independently associated with the occurrence of cardiovascular disease and severe coronary calcification was established in subjects without diabetes in a Korean population. ${ }^{20}$ Findings of our study are in similar opinion with existing literature.

Most common addiction among study subjects was tobacco chewing $(51 \%)$ followed by smoking (36\%) and alcoholism $(30 \%)$.

There was no statistically significant difference in mean value of fasting and post prandial lipid parameters among male and female $(p>0.05)$ though mean values slightly higher among females in both fasting and postprandial lipid profile hence need to target post prandial lipid profile also specially in female to prevent future cardiovascular complications.

\section{Conclusion}

Coronary artery disease and its complications can be prevented by life style modifications and behavioural change including weight reduction and abstinence from addiction like tobacco chewing, smoking and alcohol consumption. Post prandial lipid profile should also be targeted equally while treating coronary artery disease patients to prevent its future complications.

\section{References}

[1] Kim MC, Kini AS, Fuster V. Definitions of acute coronary syndromes. In: Fuster V, O'Rourke RA,Walsh RA, Poole-Wilson P, editors. Hurst's the Heart. 13th ed. New York, USA: McGraw Hill; 2011.

[2] Bashore TM, Granger CB, Hranitzky P, Patel MR. Coronary heart disease. In: McPhee S, Papakadias MA, editors. Current medical diagnosis and treatment. 49th ed. New York, USA: McGraw Hill ;2010: 316.

[3] Joshi P, Islam S, Pais P, Reddy S, Dorairaj P, Kazmi K, Pandey MR, HaqueS, Mendis S, Rangarajan S, Yusuf S. Risk factors for early myocardial infarction in South Asians compared with individuals in other countries. JAMA. 2007;297:286-294. doi: 10.1001/jama.297.3.286.

[4] Xavier D, Pais P, Devereaux PJ, Xie C, Prabhakaran $\mathrm{D}$, Reddy KS, et al. CREATE registry investigators. Treatment and outcomes of acute coronary syndromes in India (CREATE): a prospective analysis of registry data. Lancet. 2008;371:1435-1442. doi: 10.1016/S0140-6736(08)60623-6.

[5] Harikrishnan S, Leeder S, Huffman M, Jeemon P, Prabhakaran D. A Race against Time: The Challenge of Cardiovascular Disease in Developing Economies. 2nd ed. New Delhi, India: New Delhi Centre for Chronic Disease Control; 2014

[6] Yusuf S, Rangarajan S, Teo K, Islam S, Li W, Liu L et al. Cardiovascular risk and events in 17 low-, middle-, and high-income countries. $\mathrm{N}$ Engl $\mathrm{J}$ Med. 2014;371:818-827. doi: 10.1056/NEJMoa1311890.

[7] Prabhakaran D, Yusuf S, Mehta S, Pogue J, Avezum A, Budaj A et al. Two year outcomes in patients admitted with non-ST elevation acute coronary 
syndrome: results of the OASIS registry 1 and 2 . Indian Heart J.2005;57:217-225.

[8] Reddy KS, Yusuf S. Emerging epidemic of cardiovascular disease in developing countries. Circulation 1998;97:596-601.

[9] Yusuf S, Hawken S, Ounpuu S, et alThe INTERHEART Study Investigators. Effect of potentially modifiable risk factors associated with myocardial infarction in 52 countries (the INTERHEART Study): case control study. Lancet. 2004;364:937e952.

[10] Baigent C, Keech A, Kearney PM, Blackwell L, Buck G, Pollicino C, Kirby A, Sourjina T, Peto R, Collins R, Simes R. Efficacy and safety of cholesterollowering treatment: prospective meta-analysis of data from 90,056 participants in 14 randomised trials of statins. Lancet 2005;366:1267-78.

[11] Nakamura K, et al. Postprandial hyperlipidemia as a potential residual risk factor. J Cardiol (2015), http://dx.doi.org/10.1016/j.jjcc.2015.12.001

[12] Nordestgaard BG, Varbo A. Triglycerides and cardiovascular disease. Lancet 2014;384:626-35.

[13] Institute of Health Metrics and Evaluation. GBD Profile: India. http:/ www.healthdata.org/sites/default/files/files/country_pr ofiles/GBD/ihme_gbd_country_report_india.pdf.

[14] Ceriello A, Taboga C, Tonutti L, Quagliaro L, Piconi L, Bais B, Da Ros R, Motz E: Evidence for an independent and cumulative effect of postprandial hypertriglyceridemia and hyperglycemia on endothelial dysfunction and oxidative stress generation: effects of short- and long-term simvastatin treatment. Circulation 106:1211-1218, 2002

[15] Patel V, Chatterji S, Chisholm D, Ebrahim S, Gopalakrishna G, Mathers C, Mohan V, Prabhakaran D, Ravindran RD, Reddy KS. Chronic diseases and injuries in India. Lancet. 2011;377:413-428. doi: 10.1016/S0140-6736(10)61188-9.

[16] 16 .Report on Causes of Death in India 2001-2003. New Delhi, India: Office of the Registrar General of India; 2009.

[17] GBD 2015 Mortality Causes of Death Collaborators . "Global, regional, and national life expectancy, allcause mortality, and cause-specific mortality for 249 causes of death, 1980-2015: a systematic analysis for the Global Burden of Disease Study 2015". Lancet. 388 (10053): 1459 1544. doi:10.1016/S0140-6736(16)31012

1. PMC 5388903. PMID 27733281

[18] Expert Panel on Detection Evaluation and Treatment of High Blood Cholesterol in Adults. Executive summary of the third report of the National Cholesterol Education Program (NCEP) Expert Panel on Detection, Evaluation, and Treatment of High Blood Cholesterol in Adults (Adult Treatment Panel III). JAMA 2001;285:2486-2497.

[19] Teno S, Uto Y, Nagashima H, Endoh Y, Iwamoto Y, Omori Y [10]et al. Association of postprandial hypertriglyceridemia and carotid intima-media thickness in patients with type 2 diabetes. Diabetes Care. 2000;23(9):1401-06.

[20] Won et al.: Differential association between obesity and coronary artery disease according to the presence of diabetes in a Korean population. Diabetology \& Metabolic Syndrome 2014 6:134. doi:10.1186/17585996-6-134 